\title{
Comissão de Terras e Colonização de Passo Fundo e Palmeira: atuação nos toldos indígenas sob suas jurisdições
}

\author{
Land and Colonization Commission of Passo Fundo and Palmeira: action on \\ indigenous awnings under their jurisdiction
}

\section{Kalinka de Oliveira Schmitz}

Universidade de Passo Fundo - UPF - Passo Fundo - Rio Grande do Sul - Brasil

\section{Rosani Maria Martinelli Nunes}

Universidade de Passo Fundo - UPF - Passo Fundo - Rio Grande do Sul - Brasil

\begin{abstract}
Resumo: O presente texto objetiva discutir as atuações das Comissões de Terras e Colonização de Passo Fundo e Palmeira, durante as duas primeiras décadas do século XX e como o positivismo praticado pelos líderes do governo e pelo diretor da Diretoria de Terras e Colonização influenciava os trabalhos das Comissões subordinadas à eles. $\mathrm{O}$ trabalho também permite perceber as diferenças nos estágios de trabalho e colonização das áreas de administração das duas Comissão de Terras e Colonização, e quais eram as ações realizadas pelas mesmas na administração dos toldos.
\end{abstract}

Palavras-chave: Aldeamentos. Colonização. Comissão de Terras e Colonização.

Abstract: The purpose of the present text is to discuss the actions of the Commissions of the Lands and Colonization of the cities Passo Fundo and Palmeira during the first two decades of the 20th century, the text also discuss how the positivism practiced by the leaders of the government and by the director influenced the work of the commissions subordinated to them. This work shows the differences in the work and colonization stages of the administration areas by the two Commissions of Lands and Colonization, and what actions were taken in the administration of the villages.

Keywords: Villages. Colonization. Commission of Lands and Colonization 


\section{Introdução}

Os índios Kaingang ou coroados ocupavam (e ainda ocupam) a parte Norte do estado do Rio Grande do Sul, e têm em sua história, vários conflitos contra grupos que ameaçavam seu território. Primeiramente seus rivais eram os índios guaranis, presentes na grande região dos tapes. A relação destes com os índios guaranis e com missionários jesuítas fez com que se criasse a imagem de que diferentemente dos guaranis, que seriam mais desenvolvidos culturalmente, os kaingang seriam hostis por conta das correrias (ataques praticados pelas parcialidades kaingang) contra seus inimigos. Também pelo fato de que os jesuítas tentaram implantar nos Campos de Cima da Serra, missões a fim de civilizar os kaingang, porém, sem obter êxito nesse projeto (SILVA, BARCELOS, 2009).

Portanto, em um segundo momento à sua inimizade e confrontos com os guaranis, os kaingang passaram também a entrar em conflito com os portugueses, que adentravam a Província de Rio Grande de São Pedro para comércio e aprisionamento de índios como escravos que seriam vendidos no Sudeste do país. Esse foi um dos primeiros motivos pelos quais ainda no Império optouse por aldear os indígenas, a fim de civilizá-los, tornando-os mais "dóceis" e assim, diminuir os ataques realizados à tropas de comerciantes, e à propriedades pelas quais cruzavam. Esses conflitos entre luso-brasileiros e indígenas, passaram, de acordo com Rückert (1997, p. 53) a "ser entendidos como um problema que compete, progressivamente, ao governo provincial administrar".

Silva e Barcelos ainda questionam a explicação dos jesuítas sobre não terem conseguido evangelizar outros grupos além dos guaranis. Enquanto mostram que os relatos jesuítas afirmavam não terem tido êxito por conta do estado selvagem em que esses outros grupos se encontravam, os autores afirmam que é necessário levar em consideração outros fatores, tais como a falta de recursos humanos e materiais para os missionários voltarem suas atenções à outros grupos.
Esses indígenas que resistiram às investidas de aldeamento por parte dos jesuítas, são, segundo Becker (1976, p. 41) atualmente chamados de Kaingang são o que num primeiro momento denominou-se Guaianá, do ramo do tronco Jê, e ocupavam os atuais estados do Rio Grande do Sul, Santa Catarina, Paraná e São Paulo.

O território, então ocupado pelos kaingang, por possuir abundância de erva-mate, já era alvo de interesse dos espanhóis durante o século XVIII. Também os portugueses e posteriormente o governo brasileiro nutriam interesse sobre a região; o interesse na região fez com que os indígenas fossem vistos como obstáculos que deveriam ser transpostos para efetivar a conquista dessa área.

Como forma de resistência às incursões dos brancos para a ocupação de sua área de origem, os kaingang passaram então a utilizar ainda mais da violência - correrias (ataques) -. Todavia, após perceberem que apenas o uso da violência não estava ajudando na defesa de seu território, os indígenas "resolveram, em fins de 1840, adotar como estratégia a realização de alianças" (LAROQUE, 2009, p. 82-83). Nessa negociação, estava envolvida a demarcação de uma área (toldo) que seria exclusivamente dos indígenas, e a oferta de alimentos, vestuários e ferramentas para o uso na terra, tudo isso para que os indígenas se fixassem; em contrapartida, com a fixação na área demarcada, deixariam de realizar as ditas correrias, e se aproximariam de um modo de vida considerado mais civilizado de acordo com os órgãos públicos.

Os indígenas não eram percebidos pelo governo como um perigo; mas sim, como um obstáculo que deveria ser superado para o sucesso no assentamento de novos moradores, bem como para as tropas de comerciantes que passavam pela região. O fato de serem considerados apenas como obstáculos que deveriam ser transpostos para o desenvolvimento da região, mostra que eram colocados em um patamar como qualquer outro obstáculo natural ao avanço da civilização, tal como se fossem animais ferozes ou terrenos acidentados 
que dificultavam o trânsito (SILVA, BARCELOS, 2009).

Em consequência do contato com europeus e seus descendentes, o mundo indígena sofrera várias desorganizações ao longo dos séculos. Tal como os indígenas que tiveram seu cotidiano alterado com o avanço português no século XVI, os indígenas no Rio Grande do Sul também sofreram com isso. $\mathrm{Na}$ segunda desorganização sofrida pelos indígenas, um dos agentes causadores de tal processo foram os imigrantes que passaram a se estabelecer no estado como parte do projeto imperial de produção de alimentos e proteção de fronteiras com 0 estabelecimento de propriedades (DREHER, 2014).

\section{Relação entre os indígenas e a colonização}

A colonização empreendida pelo Governo provincial, na região do atual município de São Leopoldo, e a consequente ocupação da região fez com que ocorresse uma movimentação destes indígenas para a região de mata mais fechada e menos ocupada, até chegar ao norte do Rio Grande do Sul.

Posteriormente, nessa região, houve uma motivação similar à ocorrida na região de São Leopoldo para retirar os indígenas. Para liberar espaço para o movimento migratório que estava se desenvolvendo, novamente os indígenas foram sendo realocados, reorganizados, para, além de aumentar o espaço livre, restringir a mobilidade dos mesmos, bem como ter maior controle sobre os grupos kaingang.

A colonização era entendida como um meio de incorporação de regiões à uma lógica de produção capitalista. Diferentemente dos indígenas e caboclos (entendemos caboclos não como uma questão racial, mas sim como resultado de fatores sociais e culturais do meio onde viviam) que não pensavam em trabalhar a terra para fins capitalistas (apenas para seu próprio sustento), o colono, além de produzir para a sua própria subsistência, também produzia excedente para o mercado, e consequentemente, possuía uma atuação mais ativa no sistema capitalista do que os dois primeiros grupos. Dessa forma, por não estarem alinhados à lógica de produção capitalista, índios e caboclos passaram a ser excluídos; em consequência disso, Caron e Tedesco afirmam que "desterritorializados, embrenharam-se cada vez mais nas matas e nas barrancas do Rio Uruguai" (2012, p. 226).

Esse movimento que acabou por levar os índios cada vez mais para dentro das matas fechadas se deu principalmente pela visão que o estado possuía das terras. As áreas que não possuíssem um título comprobatório de propriedade seriam pertencentes ao estado (no caso, o Rio Grande do Sul), e por isso, ele poderia dispor delas como bem entendesse. A questão é que indígenas (e caboclos também), apesar de ocuparem suas terras por longa data, não possuíam um papel lhes conferindo a propriedade das mesmas; isso fez com que mesmo habitadas, essas terras fossem consideradas devolutas, e assim, disponíveis para o uso no projeto de colonização, e que seus ocupantes antigos passassem a serem reconhecidos como intrusos frente aos colonos que, por meio da compra possuíam um título de propriedade legal sobre a terra ocupada. Afinal, sem o documento sobre a área que ocupavam, índios e caboclos foram sendo cada vez mais pressionados pela colonização oficial, sendo expulsos das terras que ocupavam.

Convém destacar, porém, que os imigrantes não possuíam conhecimento que as terras que compravam, as quais eram chamadas de devolutas, possuíam ocupantes antigos. Também não sabiam que os grupos que já ocupavam as terras que estavam sendo vendidas a eles possuíam uma compreensão diferente de uso da terra. Dreher pontua essa diferença, afirmando que "para o imigrante terra era espaço fechado, cercado; para o Kaingang terra era o espaço de recursos para a sobrevivência do grupo" (2014, p. 181). Além de se tornarem proprietários das terras outrora ocupadas por indígenas, os imigrantes também prejudicavam o acesso à alimentação dos kaingang, visto que derrubavam a araucária para a construção de 
moradias; a mesma árvore que era fonte alimentar dos índios, pois fornecia o pinhão.

Os imigrantes não tomavam conhecimento de que a terra em que iriam se assentar já era ocupada há muito tempo por outros grupos. Um dos fatores para esse desconhecimento era a propaganda divulgada na Europa, tanto pelas companhias colonizadoras quanto pelo governo brasileiro, na qual não se revelava que as terras que seriam destinadas aos imigrantes não eram totalmente devolutas, ou seja, que já eram ocupadas por grupos autóctones. A supressão dessa informação era importante para que não houvesse influência negativa na imagem do país, a qual poderia ocasionar uma redução no número de imigrantes que viriam ao Brasil.

Apesar da tentativa de esconder a presença de índios e caboclos nas terras que seriam para colonização, ao chegarem ao Brasil, invariavelmente os colonos se encontravam com esses grupos quando do seu assentamento nos lotes coloniais. Desse processo de alteridade muitas vezes não amistosas, é que reforçou-se a imagem de que os kaingang seriam elementos ferozes e sanguinários.

Com essa visão do indígena como elemento perigoso para os colonos, entendia-se que era trabalho do governo proteger os colonos dos ataques efetuados pelos índios, pois defendidos, os colonos poderiam contribuir ainda mais para 0 desenvolvimento do estado, posto que não haveria outras preocupações - ataques de índios - em suas mentes.

Assim, com essa questão presente, o processo de aldeamento de indígenas se inicia no ano de 1848. Esse fato é determinante para "a efetiva expropriação de suas terras e diminuição de sua população" (RÜCKERT, 1997, p. 54), visto que com o aldeamento, além de tranquilidade para os já instalados em determinada região, serviria como propaganda afirmando que tal área estava livre dos gentios, diminuindo assim a chance de os colonos enfrentarem problemas.

Assim, através de práticas coercitivas, como por exemplo o fornecimento de alimentos e vestuário, passaram a induzir os indígenas a se assentarem nos aldeamentos. Contudo, essa prática coercitiva nem sempre funcionou completamente, tendo em vista que várias parcialidades kaingang alternavam períodos em aldeamentos e períodos nas matas, quando continuavam a realizar correrias contra comerciantes e colonos.

No contexto do século XIX, ainda durante o período imperial, criou-se com o Decreto n. 926 de 24 de julho de 1845, o Regulamento acerca das Missões de catechese, e civilização dos Indios (IOTTI, 2001). Esse decreto objetivava o fim da chamada guerra aos bugres, praticada durante a exploração do interior do território, e que fora liberada ainda no período colonial. Essa política imperial consistia em civilizar os indígenas o quanto fosse possível, através de técnicas de agricultura, de roupas, do convívio com ocidentais (brancos), com policiamento, com educação sistematizada, buscando protegê-los do extermínio e tratando da sua completa absorção pela sociedade.

Os aldeamentos, contudo, ao fim do Império não foram contemplados com o olhar dos primeiros anos da República. Por conta do modelo federativo, inspirada na constituição estadunidense, a premissa de estados com constituição própria não impunha qualquer obrigação quanto aos indígenas residentes nos estados da federação.

Isto posto, no início da República, a colonização estava ocorrendo de forma plena no Rio Grande do Sul. E é nesses primeiros de República que o governo criou a Diretoria de Obras Públicas, Terras e Colonização, com o Ato n. 015 de 31 de janeiro de 1895, como forma de reorganizar a Secretaria das Obras Públicas, com a finalidade de administrar as Comissões de Terras espalhadas pelo estado (IOTTI, 2001). Mais tarde ocorreu um desmembramento nesse órgão público, tornando-se então a Diretoria de Terras e Colonização, sob a liderança de Carlos Torres Gonçalves, praticante do positivismo religioso que buscava pôr em prática as suas ideias através do órgão público.

A Diretoria de Terras e Colonização tratava, também, da situação dos indígenas, e tinha sob sua responsabilidade a maior parte dos toldos existentes 
no estado. Com a instalação de novos toldos e a manutenção dos criados durante o Império, houve uma tranquilidade entre os colonos, decorrente da redução do território indígena.

Com a alteração da perspectiva sobre o número de indígenas e caboclos na região, constatou-se que era necessário civilizar esses elementos. É nesse momento em que o colono será visto como elemento civilizador dessa área (CARON, TEDESCO, 2012). Para reforçar o discurso de que o colono seria o agente que levaria a civilização ao sertão rio-grandense, desenvolveu-se a imagem de que antes da chegada do colono, a região era tomada pela mata (o que não deixava de ser verdade), onde a terra não era trabalhada da forma como deveria, o que contribuía para 0 atraso da região e, consequentemente, do estado.

\section{A comissão de terras e colonização e os indígenas}

Ao realizar a análise das documentações produzidas por ambas as Comissões, nas quais as chefias relatavam os trabalhos que estavam sendo realizados, foi possível observar o posicionamento desses órgãos públicos no que dizia respeito aos indígenas, e a forma como os mesmos eram tratados por cada comissão. Apesar de o cargo de chefe da Comissão ser por indicação, e ser um braço da Diretoria de Terras e Colonização (já que eram as seções regionais e a Diretoria era o órgão central), os chefes possuíam certa autonomia na atuação na região de abrangência.

Antes de iniciar a análise da documentação propriamente dita, temos que ressaltar, sobre a documentação da CTC de Palmeira que tivemos acesso, se tratava de uma transcrição dos Relatórios de Colonização; assim sendo, nessa transcrição acessada não consta a numeração das folhas de onde a informação foi retirada. Por isso, quando da citação das informações de Palmeira, constará apenas o nome do documento e o ano.

Ao analisar a atuação da Comissão de Terras e Colonização (CTC) de Passo Fundo e de Palmeira é necessário atenção ao comparar as duas CTCs, uma vez que as mesmas foram criadas com alguns anos de diferença. Enquanto a Comissão de Passo Fundo foi criada no ano de 1907, dez anos antes da Comissão de Palmeira, datada do ano de 1917.

A Comissão de Passo Fundo é criada através do decreto n. 91.090 de 17 de maio de 1907, com a orientação de organizar as terras devolutas da região (IOTTI, 2001). Além do trabalho de campo, a Comissão iria realizar outras atividades, como solicitação de construção de estradas e pontilhões, além de estabelecer a comunicação da Diretoria com as necessidades dos indígenas, de caboclos e de colonos. No relatório da Secretaria de Estado dos Negócios das Obras Públicas, do ano de 1910, na parte referente às atividades desenvolvidas pela CTC de Passo Fundo, evidencia-se o grande território de abrangência da referida Comissão, e a dificuldade que isso representava para a plena atividade da Comissão, uma vez que o número de funcionários era menor do que o necessário para a realização plena das atividades necessárias.

Essa diferença de uma década entre a fundação de cada Comissão permite compreender o movimento realizado pela colonização para o completo povoamento do estado, uma vez que as comissões iam sendo criadas de modo a acompanhar esse movimento, a fim de legalizar a questão da terra para a chegada dos colonos. Esse trabalho das Comissões, portanto, também impactava a vida dos indígenas e caboclos, tanto de formas positivas quanto negativas, pois ao mesmo tempo em que legalizava a propriedade de caboclos, mantinham os indígenas aldeados para abrir espaço à colonização.

É válido destacar que a região de atuação da CTC de Palmeira foi de fato a última do estado a ser completamente povoada (por colonos) já que já era habitada por indígenas e caboclos. A Diretoria de Terras e Colonização voltou sua atenção de fato para a região que seria responsabilidade da Comissão de Terras e Colonização de Palmeira, apenas no ano de 1908. A Comissão de Terras e Colonização de Palmeira surge então no ano de 1917, após se desmembrar da Comissão do Alto Uruguai, que por 
sua vez fora fundada no ano de 1891 (NASCIMENTO, 2007).

Ainda, apenas com a criação da Diretoria de Terras e Colonização, no ano de 1895, que a questão dos indígenas no estado recebeu a devida atenção (VANIN, TEDESCO, 2017). Anteriormente havia uma pasta que tratava da questão agrária e de colonização, contudo, como a questão indígena se relacionava com a colonização, acabaram por juntar esses temas em uma pasta apenas.

Com temas como a colonização e a questão indígenas sendo unidas nas ações a nível estadual, em 1910, há a criação em nível federal do Serviço de Proteção aos Índios e Localização dos Trabalhadores Nacionais (SPILTN), voltado especificamente para questões que envolvessem indígenas e caboclos. Sua criação se deu algum tempo depois da criação da Comissão de Terras e Colonização de Passo Fundo, e a sua alteração (voltando-se apenas à questão indígena) ocorreu apenas um ano após a criação da Comissão de Palmeira. Tal coincidência pode evidenciar possíveis mudanças nas políticas de ambas as Comissões. Essa proximidade de datas pode ter influenciado de alguma forma as ações das Comissões quanto aos indígenas.

Apesar da criação do SPI, nem todos os toldos localizados na região de estudo desse trabalho passaram à sua administração. Segundo o Mapa encontrado no Relatório da Diretoria de Terras e Colonização, os toldos no município de Passo Fundo eram: Ligeiro (único toldo administrado pelo SPILTN), Carreteiro, Ventarra, Erechim e Votouro, além dos que em 1917 passaram a administração da CTC de Palmeira, o toldo de Inhacorá, 2 toldos em Nonoai (um deles provavelmente o da Serrinha) e Guarita.

O ideário positivista também reflete-se nos relatórios, sendo um em específico somente acerca dos indígenas, os lugares que se assentaram, os trabalhos das CTCs em relação a seus territórios e os hábitos indígenas, sempre ressaltando o “...interesse digno da grande causa da proteção aos nossos silvícolas." (Relatório de 1910, p. 143).

Desde o ano de 1910, a CTC de Passo Fundo se organizava para realizar as demarcações oficiais dos toldos em sua área de abrangência; Palmeira nesse período também era área de ação dessa Comissão. Consta no Relatório da Diretoria de Terras e Colonização (1910) que os toldos do Ligeiro e do Fachinal foram demarcados com maior antecedência que os demais.

A partir da documentação da Comissão de Terras e Colonização de Passo Fundo, percebemos o convívio entre os diversos grupos que interagiam através da Comissão. Essa documentação traz elementos do cotidiano que podem passar despercebidos no momento em que acontecem, mas que, a partir da aplicação do paradigma indiciário (GINZBURG, 1989) é possível fazer uso desses elementos corriqueiros, pois através dos indícios encontrados na documentação são percebidos os elementos decisivos nos embates de relações de poder e domínio da terra.

Composta de relatórios de atividades, ofícios expedidos tratando de materiais a ser encaminhados para a Comissão, viagens de funcionários e problemas nas colônias e ofícios recebidos com ordens e recomendações diretamente da Diretoria, a documentação, na sua parte analisada, expõe determinadas situações que deixam evidente casos de favorecimento a certos grupos e/ou indivíduos em detrimento de outros.

Nesse trabalho, discutiremos apenas alguns casos presentes em correspondências e ofícios, mas que ajudam a compreender o tema. Em vista desse recorte, não será abordado todo o período de atuação das CTCs.

No livro de Correspondência de 1911 a 1912, o Chefe da Comissão Serafim Terra se corresponde, em 5 de janeiro de 1912, com o Diretor da Diretoria de Terras e Colonização, na primeira correspondência do ano:

Junto vos remeto a caderneta de campo, cálculo analítico a planta do toldo da Serrinha, no município de Palmeira, com os lotes vendidos para os intrusos que se achavam (ilegível) dentro da área medida; acompanhando também uma relação nominal dos mesmos intrusos com as respectivas áreas. (CORRESPONDÊNCIA, p. 55, 19111912) 
Nesse caso, o engenheiro chefe da Comissão passofundense intervém em favor dos invasores, mas o documento não esclarece a etnia ou a origem dos mesmos, vendendo terras de um Toldo indígena após a criação da SPILTN. Nas demais correspondências analisadas em momento algum encontrou-se uma explicação por parte da Diretoria, ou mesmo uma orientação que explicasse ou indicasse a causa dessas exceções.

O mesmo engenheiro Chefe, na correspondência $n^{\circ} 11$, de 15 de janeiro de 1912, indica como ponto de referência de um herval, a sua proximidade do Toldo indígena de Caseros, o qual não havia o conhecimento de que se tratasse de um herval pertencente ao governo ou a particulares, podendo evidenciar, então, interesses econômicos nas proximidades de território indígena e ignorando ou não se importando com o fato da utilização desse espaço como fonte de renda dos índios.

Uma correspondência mais longa entre as duas lideranças, ำ 28 do dia 29 de fevereiro de 1912, traz um problema encontrado pelo Coletor das Rendas do Estado (um cobrador do imposto territorial que percorria o estado cobrando a dívida colonial), que solicitava à Comissão de Terras e Colonização de Passo Fundo a remoção dos intrusos que naquela ocasião ocupavam as terras já delimitadas para os indígenas do toldo de Nonoai e do toldo de Serrinha, ambos pertencentes ao município de Palmeira. Esse documento, na sua segunda página, tem sua folha ilegível, dificultando os demais detalhes, porém é possível interpretar que esse funcionário da Coletoria via as terras indígenas como "terras do domínio do Estado", como as demais destinadas a colonização, e por conta disso, deveria ser liberada de intrusos, que além de não pagarem pela área ocupada, consequentemente não pagavam o imposto sobre a mesma.

Na sequência (não é possível saber se parte do mesmo documento ou de nova correspondência), trata de aparente desentendimento de um funcionário com a Comissão. Esse funcionário diz:

Quando encarregado para proceder a medição das terras dos índios, aceitei, com satisfação a incumbência, animado no propósito digno em que estava o Estado de fazer respeitar as propriedades ainda considerados e encontradas em poder dos índios. Sob essa agradável impressão iniciei o serviço nas proximidades do povoado de Nonoai cujas divisas já foram determinadas pelo levantamento do logradouro público sob o regime da Monarquia com a área de 56.478.000,00m², hoje constituído indebitamente em chácaras, invernadas etc. imediatamente ao início da medição dois fatos revoltaram o citado funcionário contra esta Comissão (ilegível) querer deixar fora da medição uma invernada próxima ao povoado, reclamada pelos índios e conhecida por todos como lhes pertencendo, e cuja invernada é ao que parece a suposta solução de conciliar interesses dos índios e do povo; e o outro fato - não me cabe perscrutar, competindo somente as autoridades a cuja guarda está o respeito e a garantia da sociedade. (CORRESPONDÊNCIA, 1911 a 1912, folhas no 94-95).

Na sequência, na mesma correspondência, consta a opinião da liderança da Comissão, como contrária à conduta do funcionário, colocando como imprescindível a inclusão da dita invernada na já citada medição. Classifica ainda como imoral a posição e insistência do dito funcionário, considerando o referido espaço como excessivo para os indígenas, e em outros trechos leva-se a deduzir que o funcionário objetivava deixar a invernada fora de uma medição que, provavelmente, destinava-se aos indígenas, ou favoreceria aos não índios, como mostrado na sequência do trecho acima transcrito, e que poderia ainda gerar problemas futuros em relação às divisas, segundo o mesmo documento.

Ainda, há a discussão de "traçar-se na planta organizada uma linha, demarcando as respectivas divisas, que será, na primeira oportunidade, estaqueada com marcos." (CORRESPONDÊNCIA 1911 a 1912, folha no 96). O fragmento acima indica outro problema entre esse funcionário e a Comissão; contudo, não aparece novamente menção a esse caso nas demais correspondências do mesmo livro, o que impossibilita visualizar um desfecho sobre esse desentendimento.

Quando Lindolpho A. Rodrigues da Silva assume a chefia da CTC de Passo Fundo em 1913, procura devolver terras aos indígenas, já que na 
gestão do seu antecessor foram dadas a intrusos (CORRESPONDÊNCIA, 1913 a 1915).

Com a criação da CTC de Palmeira no ano de 1917, ocorreu um rearranjo na administração dos Toldos existentes no Norte do estado; já que a partir dessa nova organização, os Toldos de Guarita, Serrinha e Nonoai, passaram a estar sob a tutela dessa nova Comissão.

Os Toldos indígenas (grande parte já eram aldeamentos da época do Império), eram destaques nos relatórios da Comissão, e sua citação nesses relatórios aconteciam conjuntamente ao assentamento de colonos. Percebe-se que havia uma preocupação com 0 desenvolvimentos dos aldeamentos, e da segurança dos índios frente à possíveis investidas de colonos e fazendeiros sobre as terras demarcadas.

Já no primeiro ano de ação da Comissão de Terras e Colonização de Palmeira (1917), é latente nos relatórios, dentre os quais o de 15 de março de 1917, uma preocupação com a questão dos indígenas, visto na percepção de que os indígenas aldeados precisam ter 0 acompanhamento de mestres carpinteiros (RELATÓRIO DE COLONIZAÇÃO, 1917, ofício nำ202). Esse mestre carpinteiro teria como função ajudar no desenvolvimento do toldo, bem como ensinar o básico (ler, escrever e realizar operações matemáticas) para as crianças. Essa orientação que seria fornecida pelo mestre carpinteiro teria, como finalidade última a contribuição para o desenvolvimento do toldo, quando os indígenas conseguiriam viver por sua própria conta.

Mesmo parecendo contraditório, querer contribuir para o desenvolvimento dos índios e ao mesmo tempo tutelar vários aspectos da vida no toldo, é uma posição compreensível, porque naquele período acreditava-se que os índios se encontravam em um estágio evolutivo inferior ao dos não índios, também levando em consideração os estágios de desenvolvimento pensados pelos positivistas, no qual o estado fetichista, o primeiro de três estágios de progresso, era o menos evoluído, e era justamente nesse estágio que os órgãos públicos classificavam os indígenas. Então, era tendo isso em mente que a Comissão atuava nos toldos indígenas.

Seguindo o pensamento acima, mesmo com a premissa de deixar que os próprios indígenas negociassem com colonos - principalmente arrendamentos de terras -, o relatório do dia $1^{\circ}$ de julho do mesmo ano deixava claro que mesmo assim a Comissão deveria acompanhar as negociações, dando até mesmo alguns conselhos, para que os indígenas não fossem prejudicados nessas negociações, inclusive, indicando a eles a necessidade da confecção de contratos e da forma de pagamento pelo arrendamento (RELATÓRIO DE COLONIZAÇÃO, 1917).

Ainda sobre a preocupação da presença de um mestre carpinteiro em cada toldo, dos quatro aldeamentos que se encontravam sob jurisdição da CTC de Palmeira em 1917 - Inhacorá, Guarita, Serrinha e Nonoai - somente para os dois primeiros toldos já havia sido designado um mestre carpinteiro; isso porque afirmavam estarem se deparando com dificuldades em "encontrar pessoas idôneas para os lugares de mestre carpinteiro nos toldos de Nonoai e Serrinha" (RELATÓRIO DE COLONIZAÇÃO, 1917, cópia n2). Destarte, é interessante aqui perceber a preocupação sobre a idoneidade buscada para preencher a vaga de mestre carpinteiro dos toldos, principalmente porque era esse indivíduo que ensinaria e seria exemplo de conduta para os indígenas.

Os aldeamentos, portanto, também objetivavam fazer com que os indígenas se desenvolvessem aos moldes socioculturais tidos como europeus, e, para isso, fossem alterando o uso e a prática de seus antigos costumes, além da tentativa de modificar o modo de vida primitivo, para que os índios se adaptassem aos modos modernos de produção, se aproximando do modo de vida de colonos, que eram tidos como exemplos disso. Essa tentativa de fazer com que os indígenas se aproximasse de uma produção tida como de colonos, com a produção de excedentes pelos índios, o governo iria se ressarcir do que havia dispensado no projeto de aldeamento indígena. 
Embora no início da organização da CTC de Palmeira, para que não ocorresse qualquer problema no processo de aldeamento, principalmente quando tribos que não possuíam uma boa relação entre si eram colocadas num mesmo local, os líderes eram mantidos (apesar de os toldos terem um diretor) como chefes de seus grupos, para que a acomodação dos mesmos se desse da melhor forma possível.

Essa postura seguia sendo praticada, conforme nos mostra um trecho do Ofício nำ202 do Relatório de Colonização de 1917 da Comissão de Terras e Colonização da Palmeira, onde, elencando algumas condições gerais a serem seguidas nos aldeamentos, está a seguinte colocação

\begin{abstract}
4. - Deve ser assegurada a mais completa liberdade aos Índios de se organizarem como melhor lhes parecer, e especialmente respeitadas as autoridades que houverem instituído entre si, sem indagar sobre o acerto das escolhas. Apenas se justificam, a este respeito, os conselhos que Ihes possam ser ministrados, estes mesmos com muita prudência (sem jamais esquecer o estado cerebral deles), de modo a não arriscar comprometer a conquista da confiança dos Índios, pois nesta confiança reside essencialmente o principal fundamento da eficácia de qualquer intervenção junto a eles, e, em particular, da proteção que o Estado deseja dispensar-Ihes. (RELATÓRIO DE COLONIZAÇÃO, 1917, ofício nํ202).
\end{abstract}

A Comissão da Palmeira então, expressa em seus relatórios todo o cuidado que tomavam quando - assunto era a administração dos toldos e a orientação para o desenvolvimento dos índios aldeados; cuidado esse que pode ser entendido quase como paternalista.

Como já exposto, os índios receberiam ferramentas, roupas e alimentos do governo, principalmente no início dos aldeamentos, como uma forma de coerção para a fixação das parcialidades nesses aldeamentos; as concessões de alimentos e sementes, porém, também aconteciam quando as colheitas não eram tão boas, como no ano de 1918, e ressaltadas no relatório do dia 08 de outubro do mesmo ano. Para o toldo da Serrinha, por exemplo, seria ainda necessário fornecer mais milho, tanto para a alimentação quanto para sementes (RELATÓRIO DE COLONIZAÇÃO, 1918, ofício nำ7).
A situação dos toldos não era de todo permanente. Tal como o primeiro reordenamento do atendimento dos mesmos quando da criação da CTC de Palmeira, mais tarde, em uma resenha de trabalhos efetivados pela CTC de Palmeira, era discutido um novo reordenamento dos toldos, pelo qual o toldo de Inhacorá passaria para a Comissão de Santa Rosa, e Votouro para a Comissão de Erechim; isso fez com que ficasse sob jurisdição da CTC de Palmeira os toldos de Guarita, Nonoai e Serrinha (RELATÓRIO DE COLONIZAÇÃO, 1918).

Consequência do trabalho inicial de organização da Comissão, nos anos anteriores não constava nos relatórios da Comissão o número de índios aldeados nos toldos administrados pela CTC da Palmeira. Essa situação muda em 1919, quando afirmam que no total dos três toldos sob sua responsabilidade, vivia uma população de 1.148 índios (RELATÓRIO DE COLONIZAÇÃO, 1919), sendo que a maior parte (560 deles) vivia no toldo da Guarita. Os índios que residiam neste toldo, inclusive, eram os que tinham melhor relação com os nãoíndios, comercializando com eles, diferentemente do que ocorria principalmente no toldo de Nonoai.

Dado o crescimento populacional dos toldos, a chegada muitas vezes temporárias de parcialidades, e o crescente número de colonos que se dirigiam para a região, se fazia necessário o quanto antes que as medições das áreas dos toldos fossem realizadas, para assim se fazer uma melhor verificação das fronteiras dos aldeamentos com terras de colonos.

Sobre esse assunto, então, o único problema relativo à medição de terras de toldos na região de Palmeira foi constatado no relatório no 613 , do dia 28 de outubro de 1919, quando o auxiliar de $1^{\text {a }}$ classe, agr. Annibal Couto havia admitido que seu serviço de medição no toldo de Inhacorá havia sido mal executado, mas que se prontificava para refazer todo o serviço, às suas expensas. Assim sendo, podemos considerar que a realização das medidas das áreas dos toldos havia sido satisfatória, tanto que de todos os toldos no município de Palmeira, apenas em um havia sido constatado irregularidades nas suas medições. 


\section{Considerações finais}

A partir da documentação analisada da Comissão de Terras e Colonização de Passo Fundo, fica evidente a dificuldade de seus gestores em colocar os indígenas em primeiro plano na sua atuação, pois viam os caboclos como pessoas com maior potencial produtivo que os índios, o que era uma caracterização frequente no período. Viam-se, portanto, divididos, demarcando terras aos indígenas, mas permitindo que caboclos utilizassem as terras dos toldos para a sua subsistência, vendendo títulos das referidas terras a preços simbólicos. Percebe-se então, com esse trabalho, que o filtro dos funcionários locais é parte fundamental e determinante do processo de legitimação de terras para todos os envolvidos da região do antigo município de Passo Fundo.

Todavia, esse filtro realizado pelos funcionários na CTC de Passo Fundo não é observado na documentação analisada referente à CTC de Palmeira, pois nos relatório analisados é perceptível que os funcionários tratavam da questão dos aldeamentos e questões indígenas em geral, de modo mais direto e sem transparecer alguma preferência particular. Também poderia significar que caboclos e indígenas vivessem em áreas não tão próximas quanto em Passo Fundo, o que acabava por contribuir para o não aparecimento de disputas específicas sobre a propriedade da terra, tal como ocorria em Passo Fundo e que necessitava da mediação (im)parcial dos funcionários da referida Comissão.

Há ainda a necessidade de relembrar as diferenças na formação da região dessas duas comissões. Dado que a região de Passo Fundo havia recebido colonos antes da região de Palmeira, e por esta última ter muito mais latente a presença de indígenas, necessitando consequentemente em trabalhar na organização do espaço indígena antes da fixação de colonos na zona em questão.

Essa diferença na composição da população na área de ação de cada comissão resultou nas diferenças entre os assuntos tratados nos relatórios de cada comissão, sendo os assuntos tratados pela CTC de Palmeira mais voltados à administração dos toldos e ao suporte que deveria ser dado aos indígenas, enquanto nos documentos de Passo Fundo, a questão da propriedade da terra é mais latente.

\section{Referências}

Arquivo Histórico Regional de Passo Fundo. Comissão de Terras e Colonização de Passo Fundo. Correspondência 1911 a 1912.

Arquivo Histórico Regional de Passo Fundo. Comissão de Terras e Colonização de Passo Fundo. Correspondência 1913 a 1915.

BECKER, Ítala Irene Basile. O índio Kaingáng no Rio Grande do RS. Pesquisas. São Leopoldo, Instituto Anchietano de Pesquisas, Antropologia, n" 29, 1976.

CARON, Márcia dos Santos; TEDESCO, João Carlos. $O$ Estado positivista no norte do RS: a questão da propriedade da terra e a fundação da Colônia Erechim (1890/1910). Revista História Unisinos, São Leopoldo, v. 16, n.2, p.220- 231, maio/agosto, 2012.

Centro de Documentação e Pesquisas Históricas do Alto Uruguai. Comissão de Terras e Colonização da Palmeira. Relatório de Colonização. 1917.

Centro de Documentação e Pesquisas Históricas do Alto Uruguai. Comissão de Terras e Colonização da Palmeira. Relatório de Colonização. 1918.

Centro de Documentação e Pesquisas Históricas do Alto Uruguai. Comissão de Terras e Colonização da Palmeira. Relatório de Colonização. 1919.

DREHER, Martin N. 190 anos de imigração alemã no Rio Grande do Sul - esquecimentos e lembranças. $2^{\mathrm{a}}$ edição, $2^{\mathrm{a}}$ reimpressão. São Leopoldo: Oikos, 2014.

GOLIN, Tau; BOEIRA, Nelson (coord. geral). GOLIN, Tau; KERN, Arno A.; SANTOS, M. Cristina dos (direção vol.). Povos Indígenas. Passo Fundo: Méritos, 2009. v. 5 (Coleção História Geral do Rio Grande do Sul).

GINZBURG, Carlo. Sinais: Raízes de um paradigma indiciário. In: Mitos, emblemas, sinais: morfologia e história. São Paulo: Companhia das Letras, 1989. P. 143-179.

IOTTI, Luiza Horn (Org.). Imigração e colonização: legislação de 1747 a 1915. Porto Alegre: Assembleia Legislativa do Estado do RS. Caxias do Sul: EDUCS, 2001. 
LAROQUE, L. F. Fronteiras geográficas, étnicas e culturais envolvendo os Kaingang e suas lideranças no Sul do Brasil (1889-1930). Antropologia, n. 64, Pesquisas/Instituto Anchietano, 2007.

NASCIMENTO, José Antonio Moraes do. Derrubando florestas, plantando povoados: A intervenção do poder público no processo de apropriação da terra no norte do Rio Grande do Sul. 2007. Tese (Doutorado) - Pontifícia Universidade Católica do Rio Grande do Sul, PUCRS, Porto Alegre, RS, 2007.

Relatório da Secretaria de Estado dos Negócios das Obras Públicas. Apresentado ao Exm. Sr. Dr. Carlos Barbosa Gonçalves, Presidente do Estado do Rio Grande do Sul, pelo Secretário de Estado Candido José de Godoy. 10 de setembro de 1910. Porto Alegre: Oficinas Zipográficas da Livraria do Globo. 1910. Memorial do Legislativo. Relatórios. Obras Públicas.

RÜCKERT, Aldomar A. A trajetória da terra Ocupação e colonização do centro-norte do Rio Grande do Sul - 1827 - 1931. Passo Fundo: Editora UPF, 1997.

VANIN, Alex Antônio; TEDESCO, João Carlos. Povoamento, aldeamento e colonização no norte do Rio Grande do Sul - século XIX. In: TEDESCO, João Carlos (org). Conflitos agrários no norte do Rio Grande do Sul: Indígenas e agricultores, dimensões históricas. ed. 1. Porto Alegre: EST Edições, 2017. p. 37-84. 